\title{
Effect of Corrosion Product Films Induced by Tensile Stress on P110 Casing Steels Induced in $\mathrm{CO}_{2}$ Environment
}

\author{
Yangzhong Jing, Shuliang Wang, Yuyao Chen, Mingyu Bao, Li Liu* \\ School of Materials Science and Engineering, Southwest Petroleum University, 8 Xindu Avenue, \\ Chengdu, Sichuan 610500, China \\ *E-mail: liuliswpu@163.com
}

doi: $10.20964 / 2018.08 .21$

Received: 17 April 2018 / Accepted: 29 May 2018 / Published: 5 July 2018

Corrosion product films were formed on P110 casing steels by high-temperature and high-pressure autoclave in a $\mathrm{CO}_{2}$ environment induced by tensile stress. The effects of applied tensile stress on the protection characteristics and electrochemical performance of the corrosion product films were investigated. Scanning electron microscopy, X-ray diffraction, and electrochemical workstation were employed to analyse the surface morphology, phase composition, electrochemical impedance spectroscopy, potential dynamic polarisation curve and Mott-Schottky curve of the corrosion product films formed on $\mathrm{P} 110$ casing steels in $3.5 \mathrm{wt} . \% \mathrm{NaCl}$ solution of saturated $\mathrm{CO}_{2}$ environment. Results showed that the integrated corrosion product films formed on P110 casing steels as induced by tensile stress, and the phase of these films was not changed. The applied tensile stress can result in smaller grain size of corrosion product films, increased grain boundaries and appearance of micro channels. Consequently, the corrosion potential showed a negative shift and the corrosion current density was considerably increased. Meanwhile, the charge transfer resistance decreased, and the concentration of carrier increased owing to the P110 corrosion product films in $3.5 \mathrm{wt} \% \mathrm{NaCl}$ solution filled with saturated $\mathrm{CO}_{2}$.

Keywords: P110 casing steels, $\mathrm{CO}_{2}$ environment, Tensile stress-induced, Corrosion product films, Electrochemistry

\section{$\underline{\text { FULL TEXT }}$}

(C) 2018 The Authors. Published by ESG (www.electrochemsci.org). This article is an open access article distributed under the terms and conditions of the Creative Commons Attribution license (http://creativecommons.org/licenses/by/4.0/). 